\title{
O QUE SE DISCUTE SOBRE GESTÃO POR COMPETÊNCIAS NO SETOR PÚBLICO: UM ESTUDO PRELIMINAR DAS CONSTRUÇÕES
}

\author{
THE DISCUSSION ABOUT MANAGEMENT BY \\ COMPETENCES IN THE PUBLIC SECTOR: \\ A PRELIMINARY STUDY OF THE CONSTRUCTIONS
}

Recebido 09/04/2012 Aceito 10/09/2012

Francielle Molon da Silva ${ }^{1}$ Simone Portella Teixeira de Mello² Igor Arruda Costa Torres ${ }^{3}$

\section{RESUMO}

O mundo do trabalho passa por diversas transformações associada a pessoas e desempenho. Em meio a esse cenário, a discussão sobre competências faz-se necessária, especialmente a sob as práticas de recursos humanos adotadas no setor público. Com a finalidade de instaurar um campo de reflexão, o presente estudo teve como objetivo central investigar como estão sendo discutidas, a partir de estudos de caso, as articulações entre gestão por competências e setor público. Como principais resultados identificou-se que, embora existam algumas práticas no que tange à aplicação da noção de competências, principalmente nos estudos que apontaram o investimento em capacitação e desenvolvimento, o caminho a percorrer, no que se refere à adoção do modelo de gestão por competências,ainda é longo, principalmente na esfera pública, posto que a inclusão de novas ações e práticas precisam ser implementadas e as barreiras culturais precisam ser ultrapassadas.

Palavras-chave: competências, Gestão de Pessoas, setor público.

\footnotetext{
${ }^{1}$ Possui graduação em Administração pela Universidade Federal de Pelotas - UFPEL, especialização em Gestão de Pessoas pela Universidade Católica de Pelotas - UCPEL, mestrado e doutorado em Administração pela Universidade Federal do Rio Grande do Sul - UFRGS. Atualmente é professora da Universidade Federal de Pelotas - UFPEL. Pelotas, Rio Grande do Sul, Brasil. E-mail: franmolon@ yahoo.com.br.

${ }^{2}$ Possui graduação em Economia e especialização em Administração Universitária pela Universidade Federal do Rio Grande - FURG, mestrado em Administração pela Universidade Federal de Santa Catarina - UFSC e doutorado em Educação pela Universidade Federal do Rio Grande do Sul - UFRGS. Atualmente é pós-doutoranda em Administração pela Universidade Federal de Santa Catarina UFSC e professora adjunta da Universidade Federal de Pelotas - UFPEL. Pelotas, Rio Grande do Sul, Brasil. E-mail: sptmello@gmail.com.

${ }^{3}$ Possui graduação em Administração pela Faculdade Atlântico Sul de Pelotas e especialização em Gestão Empresarial pela Fundação Getúlio Vargas - FGV. Atualmente é graduando em Ciências Econômicas pela Universidade Federal de Pelotas - UFPEL. Pelotas, Rio Grande do Sul, Brasil. E-mail: igorarrudacostatorres@gmail.com.
} 


\section{ABSTRACT}

In world of work there are many transformations associate with person and performance. In this scenario, the discussion about competences is useful, specially in the human resources practices adopted in the public sector. So, this research wanted to investigated, considering a review of literature and interviews with publics managers, how are the articulation between these subjects. Some results demonstrated that the way to implementation is beginning, however, the trajectory is long and with big difficulties such as culture and another vision and the necessity a new human resources practices implementation.

Keywords: competences, people management, public sector.

\section{INTRODUÇÃO}

Os acontecimentos que marcaram os últimos anos no cenário mundial em termos da alta competitividade, da aceleração do tempo e do capitalismo flexível revelam um diagnóstico cambiante. Fatos políticos e econômicos, em especial na cultura brasileira, como a maior exigência de clientes, a cobrança por maior eficiência, o foco governamental voltado ao desenvolvimento das camadas mais populares, concedendo acesso a crédito e à ascensão de classe, os novos estilos de gestão, a adoção de modelos de gestão que propiciem maior padronização de processos e ações, são alguns elementos que elucidam mudanças recentes os quais incidem sobre o desempenho de mercados e sociedades e, consequentemente, sobre o das organizações, tanto públicas quanto privadas.

É nesse cenário que emerge a gestão de competências como estratégia de eficácia organizacional, articulando o desenvolvimento humano e social dos colaboradores com as necessidades da gestão organizacional. Essa abordagem parece ser fruto da modernidade organizacional, que articula processos individuais e coletivos como forma de contribuir para o desenvolvimento e meIhor desempenho das organizações frente ao novo cenário cambiante de reestruturação produtiva.

Nessa perspectiva, emerge como questão norteadora para o presente estudo: como estão sendo discutidas essas articulações entre noção de competências e atuação da Gestão de Pessoas no setor público? Dessa forma, o presente artigo tem com objetivo central fazer um levantamento acerca das publicações que existem sobre a discussão da gestão por competências no setor público.

$\mathrm{Na}$ busca pelas respostas a essa indagação, pretende-se, nesse estudo, analisar alguns artigos voltados à discussão sobre o tema. Com a finalidade de abrir um campo de reflexão, preliminar e inicial, sobre o impacto da adoção de práticas de gestão, como é o caso da Gestão por Competências (amplamente difundido no contexto privado), em ambientes públicos.

Para isso, o trabalho foi estruturado apresentando a discussão sobre a noção de competências, a compreensão do contexto de atuação da Gestão de Pessoas na área pública, para, após, apresentar e discutir algumas publicações que promovem esse debate, finalizando com comentários, nos quais ficam representadas a reflexão em construção dos autores deste trabalho.

\section{O QUE SE DISCUTE SOBRE A NOÇÃO DE COMPETÊNCIAS}

Ao longo dos anos, as teorias e abordagens administrativas têm mostrado que o sucesso organizacional é resultante de diversas variáveis, desde a eficácia na Gestão de Pessoas e no gerenciamento dos processos com foco nos resultados até a prospecção de alternativas como meio de prever decisões diante de situações inusitadas.

Nessa perspectiva, pensar em um enfoque mais instrumental das competências não é suficiente. É preciso ir além das contribuições referentes aos conhecimentos, às habilidades e às 
atitudes, elementos conhecidos como CHA. A sigla implica as três dimensões da competência pela concepção de Durand (2000), na qual o conhecimento se refere ao saber o quê e o porquê e está relacionado à informação, que, quando processada e internalizada, transforma-se em conhecimento. As habilidades compreendem uma dimensão das competências relacionadas ao saber "como", ou seja, à capacidade técnica, que implica mais do que conhecimento, implica prática. Já as atitudes implicam determinação, dizendo respeito ao "querer fazer", à identidade que leva a pessoa a ir além, a comprometer-se com algo e a tomar decisões. Todavia, como salientado anteriormente, tais dimensões explicam o fenômeno por uma concepção individual e instrumental.

Assim, a partir dos anos de 1990, sob a influência europeia, mais precisamente da Escola Francesa, a qual aponta o processo como sendo parte integrante da noção de competência, o foco da competência recaiu sobre o momento da ação, sobre a continuidade e a mobilização das capacidades relacionada a "fazer a coisa certa, no momento certo" (Le BOTERF, 1994; ZARIFIAN, 2001).

A modernidade está, atualmente, a exigir um novo perfil de gestor estratégico de pessoas, no qual a qualificação já não basta e parece estar perdendo espaço para a competência, isto é, um tipo de gestor, tomador de decisão, mais prospectivo, que se aproxime da taxonomia de tipos estratégicos de Miles e Snow (2003). A atividade de liderança não é mais simples e funcional, mas extremamente complexa, constituindo um exercício difícil mas instigante. Diante disso, a gestão estratégica de pessoas tem tratado da gestão de competências, enquanto tema emergente, associando e coordenando competências individuais à construção de competências coletivas consideradas estratégicas para a organização (MASCARENHAS, 2008).

Para Baisch et al. (2012) cada modelo ou abordagem de planejamento estratégico implementado depende tanto da estrutura organizacional como das competências dos gestores nessa estrutura. Conforme os autores, o alinhamento de metas, objetivos e colaboradores da organização levam à uma eficiente e eficaz gestão estratégica da organização (BAISCH et al., 2012)

\section{A GESTÃO DE PESSOAS NO SETOR PÚBLICO}

Ao se trata de recursos humanos ou da gestão desses no setor público faz-se necessário atentar para uma realidade diversa daquela já consagrada nas organizações privadas.

No caso do Governo Federal Brasileiro, a Gestão de Pessoas baseada em modelos de gestão por competências não é propriamente antiga, mas já vem sendo difundida entre diversas instituições, considerando os processos de seleção de servidores públicos e de remuneração, por exemplo. Essas novas experiências refletem as mudanças ocorridas nos últimos anos em relação à forma de gerir pessoas, que é menos funcionalista e articula a criação e a manutenção de competências do grupo como uma forma de obter a eficiência, a eficácia e a efetividade necessária à boa implementação da política pública (SOUZA, 2004).

Porém, Souza (2004) também aponta que essas experiências hoje não têm ainda o respaldo de uma definição mais incisiva nas diretrizes de Políticas de Recursos Humanos para o setor público, inclusive por falta de maior clareza sobre o que deve ser considerado essencial nessa área e pela ocupação quase total da agenda governamental com negociações salariais e embates corporativos. Contudo, é muito possível que, a partir do momento em que o governo dispuser de instrumentos e conceitos com diretrizes para implantação, as instituições tenham que se alinhar às linhas-mestras definidoras dos processos de aplicação de sistemas de Gestão de Pessoas baseado em competências.

No âmbito da Secretária de Gestão do Ministério do Planejamento, Orçamento e Gestão, órgão responsável pela articulação de ações de capacitação gerencial e fomento do desenvolvimento de pessoas, acredita-se que o desenvolvimento e a implementação de modelos de 
gestão por competências são uma forma de dinamizar e sistematizar as diversas práticas utilizadas hoje em gestão de pessoal.

A diversidade e os diferentes escopos dos modelos de gestão por competências permitem planejar sua implementação de acordo com as peculiaridades do serviço público, como o que aconteceu, por exemplo, na seleção de servidores públicos por competências Agência Nacional de Energia Elétrica, ao abrir o Edital ESAF no59, que regia o concurso público para cargos de Analista Administrativo, Técnico Administrativo e Especialista em Regulação do Setor Elétrico. Nesse edital estão definidas 14 competências requeridas por parte da organização, dentre elas encontram-se: visão sistêmica, conduta pública, liderança, trabalho em equipe, especialização técnica etc. No corpo do edital, não se encontra qualquer vinculação entre demonstração de domínio dessas competências com a aprovação no concurso e posterior requisito para ser investido no cargo. No entanto, é um primeiro passo para a identificação dos profissionais necessários às organizações públicas atuais e uma decisão importante das organizações ao informar, já no processo seletivo, que os profissionais, no decorrer de sua carreira, serão aferidos por esses e outros critérios (SOUZA, 2004).

Sendo assim, ao tratar da Gestão de Pessoas no setor público, faz-se necessário ter o cuidado de considerá-la como sendo "o esforço orientado para o suprimento, a manutenção e o desenvolvimento de pessoas [...] em conformidade com os ditames constitucionais e legais, observadas as necessidades e condições do ambiente em que se inserem (BERGUE, 2010, p. 18)". É com base nesse debate que se encontrou, nesta pesquisa, a relevância de se considerar a gestão por competências no setor público como uma ferramenta de Gestão de Pessoas.

\section{GESTÃO POR COMPETÊNCIAS NO SETOR PÚBLICO}

Berge (2010) afirma que, embora a gestão por competências no setor público possa ser considerada uma tecnologia de gestão a qual está presente na matriz conceitual no Decreto-lei no 5.707/2006 da esfera federal, exige um esforço de apropriação dos conceitos presentes. Sendo assim, falar em competências na Gestão de Pessoas no setor público pressupõe considerar as responsabilidades associadas a um órgão ou agente público e, ainda, como meio de diferenciar pessoas em relação a tributos de desempenho.

Porém, assim mesmo, o autor destaca que a implantação, a prática e a utilização da gestão por competências no setor público não são instrumentos fáceis de se adotar, pois é necessário que se levem em conta as particularidades da área pública, como as mudanças de direção/ governo a cada quatro anos, e as questões políticas e de poder envolvidas nisso.

No caso do Governo Federal Brasileiro, a Gestão de Pessoas baseada em modelos de gestão por competências não é propriamente antiga, mas vem se difundido entre diversas instituições de forma muito rápida, indo da seleção de servidores públicos até a definição de uma parcela extra da remuneração a que poderiam fazer jus. Essas novas experiências refletem as mudanças ocorridas nos últimos anos em relação à forma de gerir pessoas: mais do que uma abordagem funcionalista de recursos humanos ou fenomenológica de desenvolvimento de talentos individuais, a criação e manutenção de competências do grupo pode ser uma alternativa para obter a eficiência, a eficácia e a efetividade necessárias à boa implementação da política pública (SOUZA, 2004).

Na gestão pública, observa-se, então, a gestão por competências associada à necessidade de profissionalismo, que é uma das diretrizes da área de desenvolvimento de pessoas no setor público. O Decreto-lei no 5.707/06 regulamenta isso à medida que demanda a implantação de processos gerenciais que propiciem melhor desempenho para as instituições. Sendo assim, o de- 
bate sobre competências gerenciais, compreendidas e implementadas na sua totalidade (capacidades, contexto e entrega), são essenciais para a condução das mudanças, uma vez que podem contribuir para o desenvolvimento de competências organizacionais, a partir do mapeamento das diferentes instâncias, possibilitando a melhoria dos resultados sociais das organizações públicas (DUTRA, 2004; RUAS, 2001). Para Dutra (2004) e Ruas (2001), a lacuna entre a discussão e a implantação do modelo da gestão por competências está na problemática adotada a partir desse ordenamento de competências, em especial na etapa do dimensionamento, na qual instituições estão tendo dificuldades de prover a dimensão das necessidades institucionais de pessoal, na medida em que, para definir modelos de alocação de vagas que contemplem a realidade da instituição, é preciso considerar o mapeamento das competências que se quer desenvolver.

\section{PROCEDIMENTOS METODOLÓGICOS}

Este é um estudo que apresenta a revisão sistemática de um conjunto de artigos disponíveis em meio eletrônico acerca do tema gestão por competências no setor público. Vale destacar que uma revisão sistemática é uma forma de pesquisa que utiliza como fonte de dados a literatura sobre determinado tema, como destacado anteriormente.

Assim, esta metodologia baseia-se na pesquisa também denominada estado da arte ou estado do conhecimento, que contribui para a discussão e o mapeamento da produção acadêmica. Seu caráter bibliográfico auxilia na discussão e no mapeamento da produção acadêmica sobre determinado tema, possibilitando ao pesquisador destacar as condições em que foram produzidas as pesquisas (FERREIRA, 2002).

De acordo com as contribuições de Linde e Willich (2003), as etapas do presente estudo configuram-se da seguinte maneira, conforme tabela 1 :

Tabela 1: passos da pesquisa

\begin{tabular}{l|l}
\hline Passos & Descrição \\
\hline 1. Pergunta: & O que se discute sobre gestão por competências no setor público? \\
\hline 2. Base de Dados: & $\begin{array}{l}\text { Periódicos disponíveis em bases do meio digital de acesso livre e artigos } \\
\text { que incorporam a base do Scientific Electronic Library Online (Scielo). } \\
\text { Tendo como recorte as publicações de 2000 a 2011. }\end{array}$ \\
\hline 3. Critérios de busca: & $\begin{array}{l}\text { Artigos que contenham a palavra "competência(s) no setor/serviço pú- } \\
\text { blico" no título, no resumo e/ou nas palavras-chave, em português, in- } \\
\text { glês ou francês. }\end{array}$ \\
\hline $\begin{array}{l}\text { 4. Aplicação dos critérios de } \\
\text { busca e possíveis exclusões: }\end{array}$ & $\begin{array}{l}\text { Artigos científicos que contemplem a discussão sobre gestão por com- } \\
\text { petências no setor público (apontando exemplos práticos de aplicação } \\
\text { da gestão, a partir da análise de casos, não apenas da citação do termo). } \\
\text { A análise focou-se em seis artigos. }\end{array}$ \\
\hline 5. Análise crítica dos artigos: & Optou-se pela realização de análise interpretativa. \\
\hline
\end{tabular}

Fonte: elaboração própria (2011).

Os passos de apresentação dos resultados e das conclusões serão detalhados na sequência do trabalho. 


\section{APRESENTAÇÃO DOS RESULTADOS}

Apresentou-se até aqui um panorama das discussões gerais sobre os temais que tangenciam a discussão de competências e Gestão de Pessoas no âmbito das organizações públicas.

Nesse capítulo, objetivou-se trazer à tona os resultados das seis pesquisas já desenvolvidas e analisadas (MARCONI, 2004; SOUZA, 2004; PIRES, et al., 2005; ZAMBERLANM, 2006; ANDRÉ, CIAMPONE, 2008; MELLO et al., 2011), articulando a Gestão de Pessoas no setor público e a gestão por competências, bem como algumas percepções dos próprios gestores públicos a respeito da implantação de uma Gestão de Pessoas baseada em competências no setor público.

Observa-se, de maneira geral que há emergência da aplicação do tema voltado a questões estratégicas, mediadas por ações e práticas também estratégicas e articuladas de Gestão de Pessoas (GRIMAND, 2009).

O estudo de Pires et al. (2005) apresenta iniciativas da Escola Nacional de Administração Pública (ENAP), que objetivam disponibilizar instrumentos para o aumento da capacidade de governo na formulação e implementação de políticas públicas, tendo como suporte metodológico as contribuições da Canada School of Public Service (CSPS).

As notas elaboradas por Pires et. al. (2005) destacam ações desenvolvidas por instituições do poder executivo, desde a definição de competências funcionais, passando pela criação de indicadores de desempenho para delimitação da estratégia organizacional, pelas avaliações 360 e em que gerentes também são avaliados pelos seus subordinados, até a elaboração de planos de desenvolvimento individuais e institucionais, em que se percebe o desenvolvimento de competências organizacionais enquanto metodologia de ação.

Marconi (2004), por sua vez, analisa a gestão de recursos humanos vigente no setor público e as políticas de recursos humanos que vêm sendo executadas. Seu estudo destaca as novas formas contratuais, como o desenho de cargos largos (com diferentes possibilidades de trilhas de desenvolvimento) e o desenvolvimento de competências. Esses cargos têm uma concepção multifuncional em relação à realização das atividades dos profissionais, aglutinando atribuições de mesma natureza de trabalho. Um exemplo são os cargos largos como Agentes Administrativos, que reúnem atividades de suporte administrativo, como as exercidas por servidores públicos de nível médio nas áreas de compras, almoxarifado e contabilidade. Nesse caso, a mobilidade funcional aparece como uma característica marcante no desenvolvimento de competências, tendo em vista as atribuições amplas dentro da mesma função, tanto no âmbito individual quanto no organizacional.

Souza (2004), ao estudar a gestão por competências no segmento federal, descreve experiências sobre o ingresso no serviço público. Recentemente, a Agência Nacional de Energia Elétrica (ANEEL) inovou inserindo em seu concurso público o item de competências requeridas para determinados cargos. A proposta, embora revele a subjetividade ainda presente no âmbito das competências, o que é passível de recursos em concursos públicos, mostra a iniciativa da agência em demonstrar, desde o edital, a política institucional da organização para captar profissionais que, se aprovados, no decorrer de suas carreiras, serão aferidos por competências requeridas, tais como: visão sistêmica, comprometimento, aprendizagem contínua, flexibilidade, liderança e criatividade.

No que se refere à educação, experiências na gestão de competências têm sido pautadas nas políticas públicas, em especial no ensino tecnológico. Todavia, as experiências parecem mais visíveis e, consequentemente, mais aceitas na regulação do ensino superior como um todo, a exemplo dos processos de avaliação de cursos, em que os descritores de competências estão presentes na concepção didático-pedagógica, no corpo docente e na própria infraestrutura das instituições avaliadas. De modo geral, grande parte dos cursos superiores das instituições de en- 
sino superior usam esses instrumentos como referencial de competências.

Zamberlan (2006), por sua vez, elucida as competências dos coordenadores de cursos de uma universidade federal brasileira, para fins de qualidade nos programas de ensino, pesquisa e extensão. $\mathrm{O}$ autor constata que esses gestores estão orientados para as competências. No entanto, observa diferenças em relação às variáveis que tratam da habilidade comportamental de trabalhar em equipe e saber se relacionar, da atitude profissional com a intenção de realizar algo e da sinergia entre conhecimento, habilidades e atitudes. A falta de atitude e de capacidade de trabalho em equipe, associada à dificuldade de relacionamento aparece com relativa influência negativa no desenvolvimento de competências organizacionais nessa pesquisa.

Já Lima et al. (2009) enfatizam a relevância vivencial no desenvolvimento de competências. Os autores destacam que o campo de competências de um membro da organização, por exemplo, agrega os elementos que lhe dão o poder de mudar a realidade, a partir de sua vontade, de seus projetos. Tais elementos são influenciados, dentre outros aspectos, pela vivência dessa pessoa, por sua formação, por sua história familiar, assim como por sua capacidade de aprendizagem, o que implica o desenvolvimento de competências ao longo da vida.

Por um outro viés, os estudos de André e Ciampone (2008) mostram uma limitação referente à adoção do modelo no que diz respeito à responsabilidade gerencial. As autoras realizaram pesquisa com dezenove gestores de uma Supervisão Técnica de Área da Secretaria Municipal de Saúde de São Paulo, revelando que a percepção dos gestores em relação às competências para gerir uma unidade básica de saúde baseia-se em uma visão simplista que influencia diretamente o modo de operacionalização das estratégias e a dinâmica das equipes, dificultando a implementação de propostas mais eficazes. Percebe-se, assim, que o despreparo dos gestores influencia diretamente o modo de operacionalização das estratégias e a dinâmica das equipes envolvidas nos serviços podendo levar à ineficácia e ineficiência dos processos.

Alguns dos relatos provenientes dos gestores públicos, que integram o projeto de pesquisa sobre competências no Setor Público, que está sendo desenvolvido na Universidade Federal de Pelotas (UFPel) (MELLO et al., 2011), indicam que, dentre as dificuldades enfrentadas, a visão individualista dos colaboradores é recorrente. A falta de adesão dos colaboradores para as ações e atividades inerentes do setor parece uma constante. Isso ocorre especialmente com aqueles servidores que não ocupam cargos de chefias. Na maior parte dos casos, os colaboradores vinculados aos investigados têm qualificação acima daquela exigida para o cargo e veem sua situação na organização como transitória, na medida em que estão realizando concursos públicos para outros cargos em outras instituições. Os profissionais buscam a formação, a capacitação, a qualificação para si, para ampliar seu perfil de empregabilidade, mas não para o coletivo, ou seja, para a equipe de colaboradores que o pesquisado gerencia.

No segmento federal, em especial, a noção de competências caminha a passos lentos, apresentando uma concepção mais individual do que coletiva. Contudo, talvez seja nesse segmento que as competências individuais e coletivas passem a ter um sentido estratégico para os gestores públicos, de modo que possamos dar o valor devido ao tema, promovendo o tempo necessário para torná-la eficaz na gestão do coletivo e, como tão salienta Oiry (apud RETOUR et al., 2011), ao observar que a invisibilidade dos instrumentos de gestão de competências começa pela escassez do debate a seu respeito. 


\section{COMENTÁRIOS FINAIS}

A partir dessas reflexões e pesquisas preliminares, destaca-se que, embora existam algumas práticas voltadas à atuação estratégica de organizações no que tange à aplicação da noção de competências, o caminho a percorrer ainda é longo, principalmente na esfera pública. Um dos motivos que levam a isso está relacionado ao fato de se considerar as vantagens e limitações na aplicação da abordagem por competências quando se trata do savoir-faire, as chamadas manhas do ofício. Essas implicam significativa habilidade da pessoa ao realizar seu trabalho em oposição aos saberes dos bacharéis ou em oposição aos cargos de hierarquia superior, na medida em que surgem em complementaridade às performances do conhecimento técnico e, consequentemente, tornam-se visíveis em seu contexto de trabalho.

Os artigos estudados apontam para o fato de que o sucesso no desenvolvimento da gestão de competências também implica reconhecer que, por esta ser uma abordagem com foco nas pessoas e um processo evolucionário com eventos planejados e espontâneos que visam transformar comportamentos e atitudes, o que leva tempo e exige paciência ao longo das ações organizacionais do dia a dia.

Então, como inferências e apontamentos finais do trabalho, é possível afirmar que há obstáculos que podem comprometer a gestão de competências. No nível individual, o que inibe o desenvolvimento de competências são fatores de ordem psicológica, desde as percepções de gerentes e colaboradores sobre suas necessidades e habilidades de aprender, suas emoções, seus sentimentos e suas reações diante dos desafios e da resolução de problemas, até fatores mais pessoais, advindos da natureza humana, como valores e crenças. No âmbito organizacional, a cultura e o próprio clima da organização podem mostrar-se como inibidores do desenvolvimento de competências, assim como a instabilidade de mercado e a competição diante de uma maior posição econômica, que, na maioria dos casos, privilegia os resultados mais do que os processos de desenvolvimento de Gestão de Pessoas.

Por fim, é necessário esclarecer que, como esse estudo faz parte de uma pesquisa em andamento, algumas limitações fazem-se presentes, como o fato de se ter analisado apenas artigos com foco exclusivo no tema em debate neste artigo. Contudo, além da gestão por competências, há outros temas emergentes quanto à Gestão de Pessoas, tais como gestão estratégica de pessoas, aprendizagem organizacional e diversidade.

Embora estes temas não sejam objeto deste estudo, são assuntos recentes, abordados por autores como Barreto et al. (2011), os quais salientam que as diferentes áreas temáticas são relevantes para os desafios e as oportunidades que as organizações enfrentam atualmente. Observa-se, então, o quanto a Gestão de Pessoas é fator crítico de sucesso para a busca de soluções no âmbito das organizações.

\section{REFERÊNCIAS}

ANDRÉ, A. M.; CIAMPONE, M. H. T. Competências para a gestão de Unidades Básicas de Saúde: percepção do gestor. In: Revista da Escola de Enfermagem da

USP, 2007; 41(Esp): 835-40. www.ee.usp.br/ reeusp.
BAISCH, L. V. et al. Gestão estratégica e as competências gerenciais no departamento de marketing: estudo de uma indústria de bebidas. In: Rev. Adm. UFSM, Santa Maria, v. 5, Edição Especial, p. 729-748, DEZ. 2012. BARRETO, L.M.T.S. et al. Temas emergentes em gestão de pessoas: uma análise da produção acadêmica. In: Rev. Adm. UFSM, Santa Maria, v. 4, n.1, p. 215-232mai./ago. 2011. 
BERGUE, S. T. Gestão de pessoas em organizações públicas. Caxias do Sul: Educs, 2010.DURAND, T. L'alchimie de La competence. Revue Française de Gestion. Paris, v.127, n.1, p.84-102, jan./fev. 2000.

DUTRA, J. S. Competências: conceitos e instrumentos para a gestão de pessoas na empresa moderna. São Paulo: Atlas, 2004.

FERREIRA, Norma Sandra de Almeida. As pesquisas denominadas "Estado da Arte". Educação \& Sociedade, Campinas, v. 23, n. 79, p. 257-272, ago. 2002.

GIL, A. C. Administração de Recursos Humanos. São Paulo, Atlas, 2004.

GRIMAND, A. Des compétences individuelles aux compétences stratégiques. Un essai de modélisation des stratégies concurrentielles fondées sur les ressources humaines In: RETOUR, D. PICQ, T. DEFÉLIX, C. Gestion des competences. nouvelles relations, nouvelles dimensions. Paris: Vuibert, 2009.

LE BOTERF, G. De La competénce. Paris: Les Editions d'Organization, 1995.LIMA, E. et al. Foco na inovação e complementaridade em equipes de direção, no desenvolvimento de novas empresas tecnológicas. In : Rev. Adm. UFSM, Santa Maria, v. 2, n. 2, p. 343-357, maio/ago. 2009.

MARCONI, N. Políticas Integradas de RECURSOS Humanos para o Setor Público. In: Programa avançado em gestão pública contemporânea. EGAP/FUNDAP, 2004.

MASCARENHAS, A. O. Gestão estratégica de pessoas: evolução, teoria e crítica. São Paulo: Cencage Learning, 2008.

MELLO, S.P.T.; SILVA, F.M; TORRES, I.A.C. Competências gerenciais no setor público. (projeto de pesquisa cadastrado COCEPEUFPel, no. 6.02.02.002). Pelotas, UFPel: 2011.

MILES, R.; SNOW, C. C. Organizational strategy, structure and process. Sanford, CA: University
Press, 2003.

OIRY, E. A dinâmica das instrumentações de gestão pelas competências: uma proposta de critérios para análise. In: RETOUR, $D$ et al. Competências coletivas: no limiar da estratégia. Porto Alegre: Bookman, 2011.

PIRES, A. Kl et al. Gestão por competências em organizações de governo. Brasília: ENAP, 2005.

RUAS, R. L. Desenvolvimento de competências gerenciais e contribuição da aprendizagem

organizacional. In: FLEURY, M. T. L.; OLIVEIRA, M. de M. Jr (orgs.).

Gestão estratégica do conhecimento: integrando aprendizagem, conhecimento e competências.

São Paulo: Atlas, 2001. p. 242-269

SOUZA, R. L. S. de. Gestão por competências no governo federal brasileiro: experiência recente e perspectivas. In: IX Congreso Internacional del CLAD sobre la Reforma del Estado y de la Administración Pública, Madrid, España, 2 - 5 Nov. 2004.

ZAMBERLAN, C. O. Orientação para a aprendizagem, gestão por competências e comprometimento organizacional nas instituições de ensino superior. Dissertação de Mestrado, PGA, UFSM, RS, 2006.

ZARIFIAN, P. Objetivo Competência: por uma nova lógica. São Paulo: Atlas, 2001. 